\title{
Evaluation of the effects of Aqueous Extract of Parkinsonia aculeata Leaves on Kidney and Liver Function Indices in Albino Rats
}

\author{
*S. Shehu and A.S. Abubakar \\ Department of Biochemistry, Usmanu Danfodiyo University, Sokoto, Nigeria \\ [*Corresponding Author: E-mail: elmafary@gmail.com]
}

\section{ABSTRACT}

The present study was designed to evaluate the reno- and hepatotoxicity effects of aqueous extract of Parkinsonia Aculeate leaves in wistar albino rats. Twenty rats were randomly divided into five groups of four animals each. Group 1 served as control, receiving only water and food, while groups 2, 3, 4 and 5 were administered graded doses of the extract at $0.60,1.20,1.80$ and $2.40 \mathrm{~g} / \mathrm{kg}$ body weight respectively, orally, once daily for 28 days. There were no mortality or behavioural changes in the acute toxicity study at single dose of $3.00 \mathrm{~g} / \mathrm{kg}$ bw for the period of 48 hours. The extract also showed no significant effect on changes in the body weights of the animals. Alanine Transaminase (ALT) activity was significantly $(p<0.05)$ decreased at the dose of $2.40 \mathrm{~g} / \mathrm{kgbw}$ of the extract. Aspartate Transaminase (AST) and Alkaline Phosphatase (ALP) activities were significantly $(p<0.05)$ decreased at the doses of 1.80 and $2.40 \mathrm{~g} / \mathrm{kgbw}$. The serum total protein and albumin concentrations were significantly $(p<0.05)$ increased at the dose of $2.40 \mathrm{~g} / \mathrm{kg} \mathrm{bw}$ of the extract. Serum creatinine, urea and uric acid levels were significantly $(p<0.05)$ increased at the doses of 1.80 and $2.40 \mathrm{~g} / \mathrm{kgbw}$. These results suggest that the aqueous extract of $P$. Aculeate leaves may be safe to the liver but toxic to the kidney and the toxicity is dose-dependent.

Keywords:Toxicity, kidney, liver, extract, Parkinsonia aculeata.

\section{INTRODUCTION}

The use of herbs and herbal products by traditional medical practitioners and the public in the treatment of many ailments has been generally considered effective. Medicinal plants are plants which contain substances that could be used for therapeutic purposes or which are precursors for the synthesis of useful drugs (Abolaji et al., 2007). Medicinal plants, since time immemorial have been used in virtually all cultures as a source of medicine. The use of traditional medicine in most developing countries as a normative basis for the maintenance of good health has been widely observed (UNESCO, 2006). The plants typically contain mixture of different chemical compounds that may act individually, additively or in synergy to improve health. A single plant may contain digestive stimulants, anti-inflammatory compounds, antioxidants, antibiotics, venotonics, diuretics (substances that enhance the elimination of waste products and toxins) and alkaloids (GuribFakim, 2006).
The general belief is that herbs are safer than orthodox drugs because they are natural, but the fact is, herbs are neither completely safe nor poisonous. The active ingredients of plant extracts are chemical substances similar to those in the purified medications and may have the same potentials to cause serious adverse effects (Ahmad et al., 2006). They are like other medicines; they may be ineffective in low amount, while in the right amounts they may prove beneficial. Their use in high quantities and over a prolonged period may be injurious to health (Lee, 2009). Research have demonstrated that many traditionally used herbal medicines are potentially toxic and some are mutagenic or carcinogenic (Bangis et al., 2006). The noteworthy contribution made by plant medicines to human health has led to its increased official and commercial interest while their toxicity benchmark depends highly on their purity and dosage (Ahmad et al., 2006). 
Parkinsonia aculeata is one of the greatlyused herbs in northern Nigeria. Its common names include; Mexican paloverde, Jerusalem thorn and Jollybean tree (Correll and Johnston, 1970). It is a medium sized tree found sparsely in the region. It is used by the traditional healers for empirical treatment of hyperglycemia without any scientific background (de Almeida et. al, 2005). In addition to these properties, $P$. aculeata has a wide range of pharmacological activities including antimalarial and antimicrobial properties (Diya et al., 2011; Spencer et al., 1947). P. aculeata is a shrubby tree, 3-10 $\mathrm{m}$ tall, smooth yellow greenish bark, branches armed with strong spines of stipule or leaf rachis origin. It is often branching near the ground with a very open crown of spreading branches and very thin dropping foliage. Its leaflets, 14-40 pairs are distinctly scattered, 2-10 mm long and 1-4 mm wide. Flowers $2-3 \mathrm{~cm}$ in diameter, pod linear cylindrical, $5-20 \mathrm{~cm}$ long, $0.6-1 \mathrm{~cm}$ wide and strongly constricted between the seeds. Seeds are 8-10 $\mathrm{mm}$ long, 4-6 $\mathrm{mm}$ wide, green nettled with brown or purple colours (Diya et al., 2011).

The amount of information on the relative safety of herbal remedies is limited compared to that of the synthetic drugs (Ernst et al., 1998). There is lack of use of standard doses and the large volume of dosages used is difficult to manage by the body, thereby causing toxicity (Lee, 2009).The present work was therefore, undertaken to evaluate the effects of aqueous extract of $P$. aculeata leaves on kidney and liver functions in albino rats. The study has been approved by the Research and Ethics Committee of Usmanu Danfodiyo University Sokoto, and all applicable international, national and institutional guidelines for the care and use of experimental animals have been strictly complied with.

\section{MATERIALS AND METHODS \\ Experimental Animals}

The study was carried out in wistar albino rats, weighing 190- $220 \mathrm{~g}$ of both sexes. The animals were purchased from animal house of the Department of Biological Sciences, Usmanu
Danfodiyo University, Sokoto. They were allowed to acclimatize to the experimental conditions in cages for a week prior to the commencement of the experiment. They were allowed to feed on pelleted poultry feed (Vital Feed) and clean water.

\section{Collection of the Plant Sample}

The leaves of $P$. aculeata were collected from the main gate area of the permanent site of Usmanu Danfodiyo University, Sokoto, Nigeria. The plant was identified by a taxonomist in the Herbarium of Botany Unit, Biological Sciences Department, Usmanu Danfodiyo University Sokoto by comparing with the existing voucher specimen (No. S216). The leaves of the plant were sheddried at room temperature for 16 days and then pulverized to coarse powder. Exactly $400 \mathrm{~g}$ of the powdered sample were soaked in 4 litres of distilled water. The mixture was filtered after 24 hours using muslin cloth. The filtrate was then evaporated in a drying cabinet at $45^{\circ} \mathrm{C}$ to obtain a concentrated extract. The concentrated extract was reconstituted in distilled water to obtain the stock concentration of the extract.

\section{Acute Toxicity Study}

The acute toxicity test was carried out based on OECD guidelines (OECD, 2001). Five rats were randomly selected and marked to permit individual identification. The animals were weighed prior to the administration of the extract. One animal served as the control while the others were administered the extract at $3 \mathrm{~g} / \mathrm{kg}$ bw, orally in a single dose using intubation cannula. Each animal was observed at intervals of 1 hour, for the first 4 hours after dosing for any sign of toxicity and subsequently at least twice daily for the next 48 hours. The animals were reweighed to determine change in weight 48 hours following dosing.

\section{Sub-chronic Toxicity Test}

Repeated toxicity study was carried out according to OECD guidelines (OECD, 2001). Twenty rats were randomly divided into five groups of four animals each $(n=4)$. Group 1 served as control, 
receiving only water and food. Groups 2, 3, 4 and 5 were given the extract at $0.60,1.20,1.80$ and $2.40 \mathrm{~g} / \mathrm{kg}$ body weight respectively. The extract was administered orally, once daily for 28 days. The body weights of the animals were evaluated a day before the start of administration and then weekly. On the $29^{\text {th }}$ day, the animals were sacrificed after overnight fast under chloroform anesthetization; the blood sample of each rat was withdrawn from carotid artery at the neck and collected into labelled centrifuge tubes. The blood samples were then centrifuged at $4000 \mathrm{rpm}$ for $15 \mathrm{~min}$. The serum was separated from the whole blood using Pasteurpipette and transferred to plain sample tubes.

\section{Liver Function Tests}

Total Protein was determined by Biuret method based on reaction of Cupric ions in an alkaline medium, which interacts with protein peptide bonds resulting in the formation of a blue-violet complex (Biuret reaction) (Hiller, 1926). Albumin was determined by Bromocresol Green method based on its quantitative binding to the indicator 3,3,5,5-tetrabromo cresol sulphonephthalein (Bromocresol green). Aspartate Aminotransferase (AST) was determined spectrophotometrically by monitoring the concentration of oxaloacetate hydrazone formed from 2,4-dinitrophenylhydrazine (Reitman and Frankel, 1957). Alanine Aminotransferase (ALT) was measured spectrophotometrically by monitoring the concentration of pyruvate hydrazone formed with 2,4dinitrophenylhydrazine (Reitman and Frankel, 1957). Alkaline Phosphatase (ALP) was determined based on $\rho$-nitrophenyl phosphate which is hydrolyzed to $\rho$-nitrophenol and inorganic phosphate by the ALP at pH 10.4 (Kind and King, 1954).

\section{Renal Function Tests}

Serum creatinine and urea were determined as described by Cheesbrough, 1991, while serum uric acid was measure according to the method described by Jung and Parekh, 1970.

\section{Statistical Analysis}

The results were analyzed by Analysis of Variance (ANOVA) using INstat3 software (San Diago, USA). Values were expressed as Mean \pm Standard Deviation (SD). Differences in Mean $( \pm S D)$ were considered significant at $p<0.05$.

\section{RESULTS AND DISCUSSION}

The present study investigates the toxicity of aqueous extract of $P$. Aculeate leaves in albino rats. Acute toxicity test of single oral dose at 3 $\mathrm{g} / \mathrm{kg}$ of the extract did not result in any death or observable, abnormal behavioural or physical changes, such as writhing, gasping, palpitation, or decreased respiratory rate in the treated rats. Therefore, the very high value of the $L D_{50}$ (greater than $3 \mathrm{~g} / \mathrm{kg}$ of bw) by oral route indicates that the aqueous extract of $P$. Aculeate leaves was non-toxic at the test doses.

There were slight and insignificant decreases in the body weights of the rats observed, which may be due to reduced fluid or water intake caused by feeling of fullness following administration of the extract. There was also no significant difference in body weights changes among the rats in the treated groups during the 28 days treatment period when compared with that of the control group (Table 2).

Table 1: Acute toxicity test on rats administered with aqueous extract of $P$. Aculeate leaves for 48 hours period.

\begin{tabular}{llllll}
\hline Group & No of animal & Mortality & Initial Weight $\mathbf{( g )}$ & Final Weight $(\mathbf{g})$ & $\begin{array}{l}\text { Behavioural } \\
\text { Changes }\end{array}$ \\
\hline A & 1 & - & 323.10 & 321.02 & None \\
B & 1 & - & 314.06 & 315.13 & None \\
C & 1 & - & 319.04 & 316.08 & None \\
D & 1 & - & 293.12 & 291.02 & None \\
\hline
\end{tabular}




\section{Nigerian Journal of Basic and Applied Science (December, 2018), 26(2): 76-81}

Table 2: Effect of administration ofaqueous extract of $P$. aculeataleaves on weekly weight changesin therats

\begin{tabular}{llllll}
\hline Group $(\mathbf{g} / \mathbf{k g})$ & Initial & 1stweek $^{\text {th }}$ & $\mathbf{2}^{\text {nd }}$ week & $3^{\text {rd }}$ week & 4 $^{\text {th }}$ week \\
\hline Control & $221.04 \pm 3.40$ & $220.10 \pm 4.60$ & $223.03 \pm 4.20$ & $225.11 \pm 4.20$ & $222.08 \pm 4.60$ \\
$\mathbf{0 . 6}$ & $241.05 \pm 5.60$ & $239.04 \pm 6.10$ & $240.06 \pm 5.40$ & $241.06 \pm 6.20$ & $241.10 \pm 6.20$ \\
$\mathbf{1 . 2}$ & $252.14 \pm 8.20$ & $247.10 \pm 8.50$ & $247.12 \pm 8.70$ & $246.13 \pm 8.20$ & $243.06 \pm 8.30$ \\
$\mathbf{1 . 8}$ & $288.06 \pm 7.30$ & $284.09 \pm 7.20$ & $281.07 \pm 7.10$ & $280.07 \pm 7.50$ & $276.07 \pm 7.40$ \\
$\mathbf{2 . 4}$ & $202.02 \pm 4.20$ & $198.12 \pm 4.80$ & $194.02 \pm 4.50$ & $188.10 \pm 6.40$ & $186.02 \pm 7.10$ \\
\hline
\end{tabular}

Values are mean \pm Standard Deviation $(\mathrm{n}=4) .{ }^{*}=$ Significantly different from control $(\mathrm{p}<0.05)$ using Analysis of Variance (ANOVA).

The biochemical parameters related to hepatic function namely; ALT, AST, ALP, Total protein and Albumin presented in Table 3 revealed that the serum concentrations of ALT and AST following administration of the extract were significantly $(p<0.05)$ decreased when compared with the control group. This further decreases with increasing concentrations of the extract. However, the difference observed at the doses of $0.60-1.20 \mathrm{~g} / \mathrm{kgbw}$ was not significant $(\mathrm{p}<0.05)$. The levels of ALT and ALT in the groups treated with $1.80-2.40 \mathrm{~g} / \mathrm{kg}$ bw were also significantly $(p<0.05)$ decreased compared with the control group. This may therefore, imply that administration of the extract to the rats has not caused any observable sub-lethal injuries to the hepatocytes or the bile ducts because these transaminases are intracellular enzymes that tend to leak out upon injury to the cell in which they reside (Yusuf et al., 2012). AST and ALT are good indicators of hepatocytes damage when they are determined together, but ALT is more exclusively important in liver function than AST, as the latter is also found in cardiac and skeletal muscles, as well as in bones and red blood cells (Zakin and Boyer, 1996).

Serum ALP significantly $(p<0.05)$ decreases with increasing concentration of the extract, but this was not significant in groups administered with $0.60-1.20 \mathrm{~g} / \mathrm{kg}$ bw (Table 3). The low activity of alkaline phosphatase across the groups indicates that the integrity of the bile duct is intact. ALP is an indicator of biliary obstruction. The enzyme is known to regulate the secretary activities of the intrahepatic biliary epithelium (Alvaro et al., 2000; Lorke, 1983). ALP activities are also known to be elevated in coliac and ileal diseases as well as following increases in osteoblastic events (Preussner and Harold, 2008). ALP being an intracellular enzyme located in the epithelial cells lining the biliary duct, implies that the extract did not have significant effects on the liver and/or intestine.

Serum concentrations of albumin and total protein (Table 3 ) were found to be significantly increased $(p<0.05)$ in the groups treated with $2.40 \mathrm{~g} / \mathrm{kg}$ bw of the extract when compared with the control and this was also dose-dependent. This indicates that the biosynthetic abilities of the hepatocytes were not impaired by the administration of the extracts of $P$. aculeata. Serum protein being synthesized by the liver makes the serum total protein and albumin good makers of liver biosynthetic functions (Kirsch et al., 1968).

The serum concentrations of urea, creatinine and uric acid were increased but not significant in the groups administered with 0.6 and $1.20 \mathrm{~g} / \mathrm{kg}$ bw of the extract (Table 4). This suggests that the kidney function may not have been tempered by the extract at these doses. However, the concentration of serum urea was significantly $(p<0.05)$ increased in the groups treated with 1.80 and $2.40 \mathrm{~g} / \mathrm{kg} \mathrm{bw}$ of the extract. Several studies have reported elevated levels of creatinine and urea in cases of injuries to the kidney tissues (Braide and Anika, 2009; Aba and Asuzu, 2015). Uric acid and creatinine concentration were also significantly $(p<0.05)$ elevated in groups treated with 1.80 and 2.40 $\mathrm{g} / \mathrm{kg}$ bw of the aqueous extract. Therefore, at the doses above $1.80 \mathrm{~g} / \mathrm{kg}$ bw the extract could be toxic and detrimental to the kidneys. 
Table 3: Effects of administration of aqueous extract of $P$. aculeataleaves on liver function in the rats.

\begin{tabular}{llllll}
\hline Dose $(\mathrm{g} / \mathrm{kg})$ & $\mathrm{ALT}(\mathrm{U} / \mathrm{L})$ & AST $(\mathrm{U} / \mathrm{L})$ & ALP $(\mathrm{U} / \mathrm{L})$ & $\mathrm{TP}(\mathrm{g} / \mathrm{dL})$ & $\mathrm{ALB}(\mathrm{g} / \mathrm{dL})$ \\
\hline Control & $20.50 \pm 0.71$ & $57.67 \pm 4.73$ & $256.68 \pm 4.55$ & $5.66 \pm 0.18$ & $3.86 \pm 0.49$ \\
0.6 & $19.00 \pm 2.00$ & $55.00 \pm 4.24$ & $238.42 \pm 1.15$ & $4.89 \pm 0.98$ & $2.76 \pm 1.51$ \\
1.2 & $16.75 \pm 3.25$ & $58.33 \pm 2.25$ & $229.76 \pm 4.42$ & $5.23 \pm 3.44$ & $3.34 \pm 0.40$ \\
1.8 & $14.92 \pm 0.50$ & $51.33 \pm 4.10^{* *}$ & $224.48 \pm 3.90^{*}$ & $9.75 \pm 1.21$ & $3.89 \pm 0.50$ \\
2.4 & $13.50 \pm 0.50^{*}$ & $47.57 \pm 2.07^{* *}$ & $217.12 \pm 3.94^{*}$ & $11.41 \pm 0.39^{*}$ & $5.91 \pm 0.55^{*}$ \\
\hline
\end{tabular}

Values are expressed as mean \pm Standard Deviation $(n=4) .{ }^{*}=$ Significantly different from control $(p<0.05)$ using Analysis of Variance (ANOVA). ALT- Alanine Transaminase, AST- Aspartate Transaminase, ALP- Alkaline Phosphatase, TP- Total Protein, ALB- Albumin.

Table 4: Effects of administration of aqueous extract of $P$. aculeataleaves on kidney functions in the rats.

\begin{tabular}{llll}
\hline Dose $(\mathrm{g} / \mathrm{kg})$ & Urea $(\mathrm{mg} / \mathrm{dL})$ & Creatinine $(\mathrm{mg} / \mathrm{dL})$ & Uric acid $(\mathrm{mg} / \mathrm{dL})$ \\
\hline Control & $6.21 \pm 0.40$ & $0.65 \pm 0.80$ & $21.35 \pm 3.40$ \\
0.60 & $6.61 \pm 0.10$ & $0.70 \pm 0.10$ & $17.26 \pm 1.40$ \\
1.20 & $6.84 \pm 0.10$ & $0.76 \pm 0.20$ & $21.72 \pm 2.10$ \\
1.80 & $7.38 \pm 1.50^{*}$ & $0.79 \pm 0.20^{* *}$ & $26.23 \pm 1.30^{*}$ \\
2.40 & $7.50 \pm 0.40^{* *}$ & $0.84 \pm 0.40^{* *}$ & $27.69 \pm 2.20^{* *}$ \\
\hline
\end{tabular}

Values are expressed as mean \pm Standard Deviation $(n=4) .{ }^{*}=$ Significantly different from control $(p<0.05)$ using Analysis of Variance (ANOVA).

\section{CONCLUSION}

From the results of this study, it was concluded that the aqueous extract of $P$.aculeataleaves did not pose any toxicological injury to the liverat the tested doses. The extract may also be safe for the kidneysup to a dose of $1.20 \mathrm{~g} / \mathrm{kg}$ bw,butmay be toxic and detrimental to its functions at doses above $1.80 \mathrm{~g} / \mathrm{kg}$ bw.It is therefore logical to state that the plant may be considered safewithin the sub-toxic levels.

Funding: No funding was received for this research

Conflict of interest:The Authors declare no competing interests.

\section{REFERENCES}

Aba, P.E. and Asuzu, I.U. (2015). Effects of Administration of Methanol Root Bark Extract of Cussoniaarborea on Serum Biochemical Markers of kidney Damage and renal Histomorphology of Alloxaninduced Diabetic rats. Journal of
AdvancedMedicaland Pharmaceutical Sciences, 5(2):1-9.

Abolaji, O.A., Adebayo,A.H. and Odesanmi, O.S. (2007). Nutritional qualities of three medicinal plant parts commonly used by pregnant women in western part of Nigeria. Pakistan Journal of Nutrition, 6: 665-668.

Ahmad, I.,Farrukh, A., Amad, F., Owais, M. (2006). Herbal Medicine: Prospects and Constraints. In Ahmad I., F. Aquil and M. Owais Modern Phytomedicine: Turning Medicinal Plants into Drugs. Wiley-VCH Verlag GmbH \& Co., Germany, 59-78.

Alvaro, D., Benedetti, A.,Marucci, L.,Delle, M.M., Monterubblanesi, R., Di Cosimo, E., Perego, L., Macarri, G., Glaser, S., Le Sage, G. and Alpini, G. (2000). The function of alkaline phosphatase in the liver: regulation of intrahepatic biliary epithelium secretary activity in the rat. Hepathology, 32(2):174-184.

Bangis, C.I., Derey, G.,Baumelou, A., Quintrec, M.L. and Vanherweghem, J.L. (2006). 


\section{Nigerian Journal of Basic and Applied Science (December, 2018), 26(2): 76-81}

Herbs and the kidneys. American journal of kidney diseases, 44: 210-213.

Braide, L.M. and Anika, S.M. (2009). Environmental Toxicology, $1^{\text {st }}$ edition SNAAP Press Ltd, Enugu. Pp 89-99.

Cheesbrough, M. (1991). Medical laboratory manual for tropical countries. ELSB, Cambridge. 1 (7th ed). 508-511.

Correll, D.S. and Johnston, M.C. (1970). Manual of the Vascular Plants of Texas. Texas Research Foundation. Runner, Texas, USA. P: 1881.

de Almeida, C. F. C. B. R. Silva, T. C. D. E. de Amorim, E. L. C. Maia, M. B. D. S. and de Albuquerque, U. P. (2005). Life strategy and chemical composition as predictors of the selection of medicinal plants from the Caatinga (Northeast Brazil). Journal of Arid Environments, 62(1): 127-142.

Diya, B., Mruthunjaya, K. and Manjula, S.N. (2011). Parkinsonia aculeata: A Phytopharmacological Review. Asian Journal of Plant Sciences, 10: 175-181.

Ernst, E., Rand J.I. andStevenson C. (1998). Complementary therapies in depression: an overview. Archives of General Psychiatry, 1026-32.

Gurib-Fakim, A. (2006). Medicinal plants tradition of yesterday and drugs of tomorrow. Molecular Aspect of Medicine, 27: 1-93.

Hiller, A. (1926). Biuret Method. Procedures in Experimental Biology and Medicine. 24:385.

Jung, D.H. and Parekh, A.C. (1970). An improved reagent system for the determination of serum Uric acid. Clinical Chemistry, 16: 247-250.

Kind, P.R. and King, E.J. (1954). Estimation of plasma phosphatase by determination of hydrolysed phenol with amino antipyrine. Journal of Clinical Pathology, 7: 322-326.

Kirsch, R., Frith, L., Black, E. and Hoffenberg, R. (1968). Regulation of albumin synthesis and catabolism by alteration of dietary protein. Nature, 217: 578-579.

Lee, M. (2009). Basic Skills in Interpreting Laboratory Data. ASHP. ISBN 978158528-180-0. p. 259.

Lorke, D. (1983). A new approach to practical acute toxicity testing. Archives Toxicology 54:275 - 287.

OECD (2011). Acute and Oral Toxicity- Up and Down procedure. Guidelines for testing of chemicals. 1-26.

Preussner, H.T. and Harold, T. (1998). Detecting Coliac disease in your patients. American Family Physician, 57(5): 1023-1034.

Reitman, S. and Frankel, S. (1957). Colorimetric method for the determination of serum glutamic oxaloacetic and glutamic pyruvic transaminases. American Journal of Clinical Pathology, 28: 56-63.

Spencer, F.R.,Koniuszy, E.F. and Rogers, L. (1947). Survey of plants for antimalarial activity. Lloydia, 10(3): 145-174.

UNESCO (1996). Culture and health orientation texts- world decade for cultural development 1988-1997, Document CLT/DEC/PRO- 1996, Paris, France. 126.

Yusuf, A.B., Umar, I.A. and Nok, A.J. (2012). Effects of methanol extract of Vernonia amygdalina leaf on survival and some biochemical parameters in acute Trypanosoma brucei brucei infection. African Journal of Biochemical Research, 6(12): 150-158.

Zakin, D. and Boyer, T.D. (1996).Hepathology: A textbook of liver diseases.WB Saunders, Philadelphia. $3^{\text {rd }}$ ed.791-833. 